\title{
LARGE-SCALE EXPERIMENTS OF TSUNAMIS GENERATED BY ICEBERG CALVING
}

\author{
VALENTIN HELLER(1), TOMMASO ATTILI(1,2), FAN CHEN(1), MARKUS BRÜHL (3), ROMAN GABL ${ }^{(4)}$, XUEXUE \\ CHEN $^{(5)}$, GUIDO WOLTERS ${ }^{(6)} \&$ HELGE FUCHS $^{(7)}$
}

\author{
(1) Environmental Fluid Mechanics and Geoprocesses Research Group, Faculty of Engineering, University of Nottingham, Nottingham \\ NG7 2RD, UK, valentin.heller@nottingham.ac.uk; fan.chen@nottingham.ac.uk \\ (2) Department of Energy, System, Land and Construction Engineering (DESTEC), University of Pisa, Via Gabba 22, I-56100 Pisa, Italy, \\ tommasoattili4@gmail.com \\ (3) Delft Center for Systems and Control, Faculty of Mechanical, Maritime and Materials Engineering, Delft University of Technology, Delft, \\ The Netherlands, m.bruehl@tudelft.nl \\ (4) School of Engineering, Institute for Energy Systems, University of Edinburgh, Edinburgh, EH9 3DW, UK and Unit of Hydraulic \\ Engineering, University of Innsbruck, Technikerstrasse 13, 6020 Innsbruck, Austria, roman.gabl@ed.ac.uk \\ (5) Royal HaskoningDHV, George Hintzenweg 85, 3009 AM Rotterdam, The Netherlands, xuexue.cheung@gmail.com \\ (6) Deltares, Coastal Structures and Waves, Boussinesqweg 1, 2629 HV Delft, The Netherlands, guido.wolters@deltares.nl \\ (7) Laboratory of Hydraulics, Hydrology and Glaciology (VAW), ETH Zurich, 8093 Zurich, Switzerland, fuchs@vaw.baug.ethz.ch
}

\begin{abstract}
Iceberg calving at outlet glaciers contributes to global sea-level rise in the context of climate change. This study investigates tsunamis generated by iceberg calving, so-called iceberg-tsunamis. Such tsunamis reached amplitudes of $50 \mathrm{~m}$ in the recent past and endanger human beings and coastal infrastructure. 66 unique largescale experiments have been conducted in a $50 \mathrm{~m} \times 50 \mathrm{~m}$ large basin. These experiments involved the five iceberg calving mechanisms: A: capsizing, B: gravity-dominated fall, C: buoyancy-dominated fall, D: gravitydominated overturning and E: buoyancy-dominated overturning. Gravity-dominated icebergs essentially fall into the water body whereas buoyancy-dominated icebergs essentially rise to the water surface. The icebergtsunamis from gravity-dominated mechanisms ( $B$ and $D)$ are roughly an order of magnitude larger than from mechanisms $\mathrm{A}, \mathrm{C}$ and $\mathrm{E}$. The maximum wave heights and their decay with distance from the calving locations are correlated with six dimensionless parameters, where the Froude number, the relative iceberg width and the relative released energy were identified as the most important ones. Empirical equations for preliminary icebergtsunami hazard assessment for the five iceberg-calving mechanisms individually and all mechanisms combined were derived predicting the wave heights reasonably well. Ongoing and future work aims to analyse the wave parameters in further detail, compare iceberg- with landslide-tsunamis and investigate iceberg-tsunamis numerically.
\end{abstract}

Keywords: Iceberg calving; Iceberg-tsunami; Impulse wave; Outlet glacier; Physical modelling.

\section{INTRODUCTION}

Iceberg calving accounts for a significant part of the mass losses of the Antarctic and Greenland Ice Sheets and contributes to global sea-level rise in the context of climate change (Hanna et al., 2013; Enderlin et al., 2014). Iceberg calving generates so-called iceberg-tsunamis (Heller et al., 2019b). Significant iceberg-tsunamis have been observed in Greenland at the Eqip Sermia glacier where a wave amplitude of $50 \mathrm{~m}$ destroyed some infrastructure in 2014 (Lüthi and Vieli, 2016) and at the Helheim outlet glacier where approximately $25 \mathrm{~km}$ from the glacier front the measured wave was still $24 \mathrm{~cm}$ large (Vaňková and Holland, 2016). An iceberg-tsunami was also observed at the mountain glacier Tasman Glacier in New Zealand in 2011 (Dykes et al., 2016) and iceberg-tsunamis generated by capsizing icebergs destroyed a Greenlandic harbour in 1995 (N24, 2009).

Figure 1(a,b) shows iceberg calving events in nature. The icebergs interact with the surrounding water via different iceberg calving mechanisms (Benn et al., 2007; Massel and Przyborska, 2013; Minowa et al., 2018; Heller et al., 2019a,b). Five idealised mechanisms have been investigated in this work as illustrated in Figure 1(c): A: capsizing, B: gravity-dominated fall, C: buoyancy-dominated fall, D: gravity-dominated overturning and $\mathrm{E}$ : buoyancy-dominated overturning. Gravity-dominated icebergs essentially fall into the water body whereas buoyancy-dominated icebergs essentially rise to the water surface. The current understanding of icebergtsunamis is limited and only small-scale flume experiments of the capsizing mechanism A (Burton et al., 2012) have been conducted thus far.

The tsunamigenic potentials of mechanisms $A$ to $E$ have been investigated in a $50 \mathrm{~m} \times 50 \mathrm{~m}$ large wave basin. The main objectives were (i) to quantify the iceberg-tsunami features under variation of the iceberg calving mechanisms (capsizing, fall, overturning), the iceberg volume and kinematics, (ii) to compare the new findings to established empirical equations for landslide-tsunamis and (iii) to provide benchmark test cases to 
the numerical modelling community and apply them to calibrate and validate own numerical simulations (Heller, 2019; Heller et al. 2019a). This article provides a general overview about the experiments and presents some key results and empirical equations to predict the iceberg-tsunami heights. The numerical simulations of the experiments are presented by Chen et al. $(2019 a, b)$.

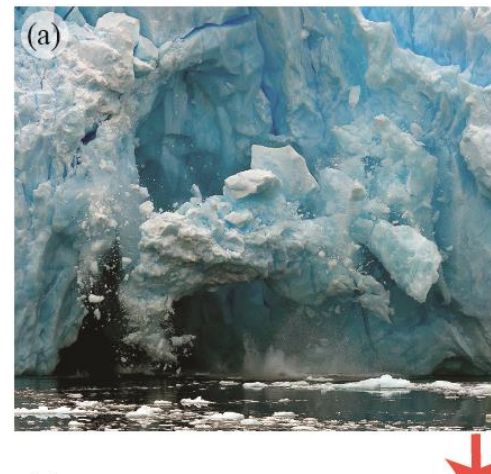

(c) A: Capsizing


Fall
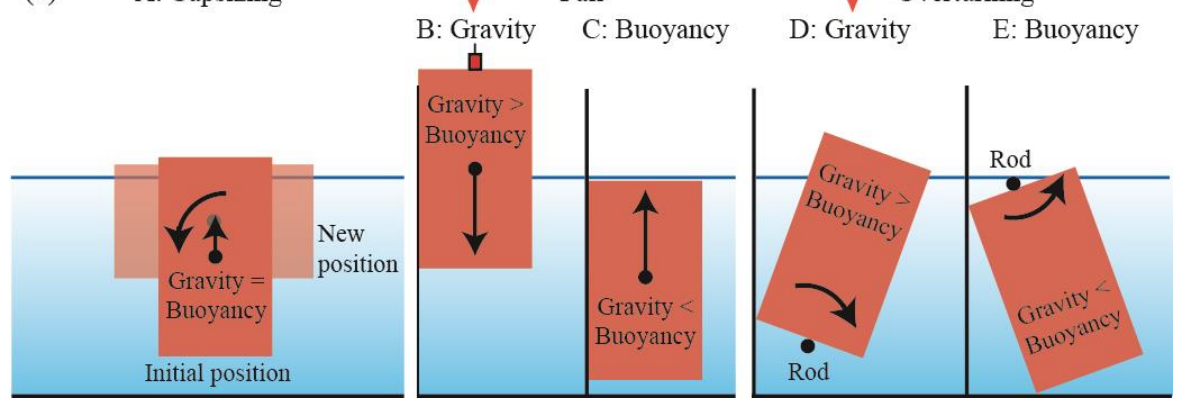

Figure 1. Real and idealised iceberg calving and iceberg-tsunami generation: (a) falling iceberg at Neko Harbour, Antarctica (courtesy of Alek Komarnitsky - www.komar.org), (b) overturning iceberg at Perito Moreno Glacier, Argentina (courtesy of Victor Qixiang Chen - http://photo.qyer.com/7259134/allphoto), (c) sketches of investigated idealised iceberg calving mechanisms from left to right: A: capsizing, B: gravity-dominated fall, C: buoyancy-dominated fall, D: gravity-dominated overturning and E: buoyancy-dominated overturning (Heller et al., 2019b).

\section{EXPERIMENTAL METHOD}

\subsection{Experimental procedure}

The experiments have been conducted under Froude similarity in the $50 \mathrm{~m} \times 50 \mathrm{~m}$ basin at Deltares in Delft, as shown in Figure 2. Blocks consisting of polypropylene homopolymer with a density similar to ice $(\approx 920$ $\mathrm{kg} / \mathrm{m}^{3}$ ) were released offshore (capsizing, Figure 1c) and at the vertical boundary of the basin (fall, overturning, Figures 1c and 2). The sizes of the two blocks were $0.800 \mathrm{~m} \times 0.500 \mathrm{~m} \times 0.500 \mathrm{~m}$ (block type 1, Figure 2) and $0.800 \mathrm{~m} \times 0.500 \mathrm{~m} \times 0.250 \mathrm{~m}$ (block type 2) and they weighted up to $187 \mathrm{~kg}$.

The experimental programme is shown in Table 1 and included 66 experiments (55 individual tests plus 11 repetitions) and two water depths $h=1.000$ and $0.750 \mathrm{~m}$. The capsizing mechanism involved 16 experiments, the fall mechanism 30 (21 gravity- and 9 buoyancy-dominated) and the overturning mechanism 20 (14 gravityand 6 buoyancy-dominated) experiments. Videos of the experiments are available in Heller et al. (2019b). The experimental procedures for the five calving mechanisms (Figure 1c) were as follows:

Capsizing (mechanism A in Figure 1c): The blocks in the capsizing case were hold in position with a wooden rod guided through the centre of the blocks. This rod was hold in position on both sides with steel profiles and was able to heave (but not to sway or surge) and pitch. The rotation of the block was initiated in most cases by removing a fitting which stabilised the block. Block type 1 had to be slightly pushed by hand, with a force in the order of $1 \mathrm{~N}$, to capsize. In some tests the blocks were pushed harder to investigate the effect of an increased rotation speed on the wave features.

Fall (mechanisms B and C in Figure 1c): The blocks were hold in position with an electromagnet prior to release, which was connected to a rope as shown in Figure 2. The supporting frame for this electromagnet and the blocks was fixed to a steel plate at the basin wall. The blocks were moved in vertical direction with a winch system which was fixed to a support structure outside the wave basin (Figure 2). For the buoyancy-dominated fall case, the block was pulled under water with a rope attached to the centre of the block bottom to oppose the buoyancy force of up to $150 \mathrm{~N}$. For some buoyancy-dominated tests the block had to be stabilised in addition with a steel beam from above and both the steel beam and the rope were then released simultaneously. 
Overturning (mechanisms D and E in Figure 1c): The blocks rotated around a fixed steel rod of $30 \mathrm{~mm}$ diameter. This rod was fed through two ball bearings fixed to the block surface. This ensured that the blocks underwent a pure rotation and no translation. The rod was hold in position on the sides with steel profiles (Figure 2). The rod was located either below (gravity-dominated mechanisms) or above (buoyancy-dominated mechanisms) the block. For some buoyancy-dominated tests the block had to be stabilised in addition with a steel beam from above and the blocks started to move once the steel beam was removed.

Table 1. Experimental parameters of all 66 conducted experiments involving the five iceberg calving mechanisms A to E; the number of tests marked with + included repetitions. SWL = still water level and Neut. = Neutrally.

\begin{tabular}{|c|c|c|c|c|c|c|c|}
\hline Block parameters & \multicolumn{3}{|c|}{ (i) Capsizing (mechanism A) } & \multicolumn{4}{|c|}{ (iii) Overturning (mechanism D and E) } \\
\hline Block release location & Offshore & Offshore & Offshore & At shore & At shore & At shore & At shore \\
\hline Block type & 1 & 2 & 2 & 1 & 2 & 2 & 2 \\
\hline Block length $l(\mathrm{~m})$ & 0.800 & 0.800 & 0.500 & 0.800 & 0.800 & 0.500 & 0.500 \\
\hline Block width $b(\mathrm{~m})$ & 0.500 & 0.500 & 0.800 & 0.500 & 0.500 & 0.800 & 0.800 \\
\hline Block thickness $s(\mathrm{~m})$ & 0.500 & 0.250 & 0.250 & 0.500 & 0.250 & 0.250 & 0.250 \\
\hline Block volume ${ }_{s}\left(\mathrm{~m}^{3}\right)$ & 0.200 & 0.100 & 0.100 & 0.200 & 0.100 & 0.100 & 0.100 \\
\hline Block density $\rho_{s}\left(\mathrm{~kg} / \mathrm{m}^{3}\right)$ & 929 & 924 & 924 & 936/923 & 912 & 912 & 936/912 \\
\hline Block mass $m_{s}(\mathrm{~kg})$ & 185.8 & 92.4 & 92.3 & $187.1 / 184.6$ & 91.2 & 91.2 & $93.6 / 91.2$ \\
\hline Water depth $h(\mathrm{~m})$ & 1.000 & 1.000 & 1.000 & 1.000 & 1.000 & 1.000 & 0.750 \\
\hline $\begin{array}{l}\text { Release position above SWL }(\mathrm{cm}) \\
(0 \mathrm{~cm} \text { corresponds to the } S W L)\end{array}$ & Neut. buoyant & Neut. buoyant & Neut. buoyant & $\begin{array}{c}15,0,-30 \\
-60,-90\end{array}$ & $\begin{array}{r}15,0,-30 \\
-60,-90\end{array}$ & $\begin{array}{c}15,0,-30 \\
-60\end{array}$ & $\begin{array}{c}15,0,-30 \\
-60\end{array}$ \\
\hline Number of runs (66 in total) & $5^{+}$ & $6^{+}$ & $5^{+}$ & 5 & 5 & 4 & $6^{+}$ \\
\hline
\end{tabular}

\begin{tabular}{|l|cccccc|}
\hline \multicolumn{1}{|c|}{ Block parameters } & \multicolumn{7}{c|}{ (ii) Fall (mechanism B and C) } \\
\hline Block release location & At shore & At shore & At shore & At shore & At shore & At shore \\
Block type & 1 & 2 & 1 & 1 & 2 & 2 \\
Block length $l(\mathrm{~m})$ & 0.800 & 0.800 & 0.500 & 0.500 & 0.500 & 0.500 \\
Block width $b(\mathrm{~m})$ & 0.500 & 0.500 & 0.800 & 0.800 & 0.800 & 0.800 \\
Block thickness $s(\mathrm{~m})$ & 0.500 & 0.250 & 0.500 & 0.500 & 0.250 & 0.250 \\
Block volume $F_{s}\left(\mathrm{~m}^{3}\right)$ & 0.200 & 0.100 & 0.200 & 0.200 & 0.100 & 0.100 \\
Block density $\rho_{s}\left(\mathrm{~kg} / \mathrm{m}^{3}\right)$ & $936 / 923$ & $936 / 912$ & $936 / 923$ & $936 / 923$ & $936 / 912$ & $936 / 912$ \\
Block mass $m_{s}(\mathrm{~kg})$ & $187.1 / 184.6$ & $93.6 / 91.2$ & $187.1 / 184.6$ & $187.1 / 184.6$ & $93.6 / 91.2$ & $93.6 / 91.2$ \\
Water depth $h(\mathrm{~m})$ & 1.000 & 1.000 & 1.000 & 0.750 & 1.000 & 0.750 \\
Release position above SWL $(\mathrm{cm})$ & $0,-30,-60$, & $0,-30,-60$, & $30,0,-30$, & $30,0,-30$, & $30,0,-30$, & $30,0,-30$, \\
$(0$ cm corresponds to the SWL) & -84 & -83 & $-60,-70,-83$ & -60 & $-60,-83$ & -60 \\
Number of runs $(66$ in total) & $6^{+}$ & 4 & $7^{+}$ & 4 & 5 & 4 \\
\hline
\end{tabular}

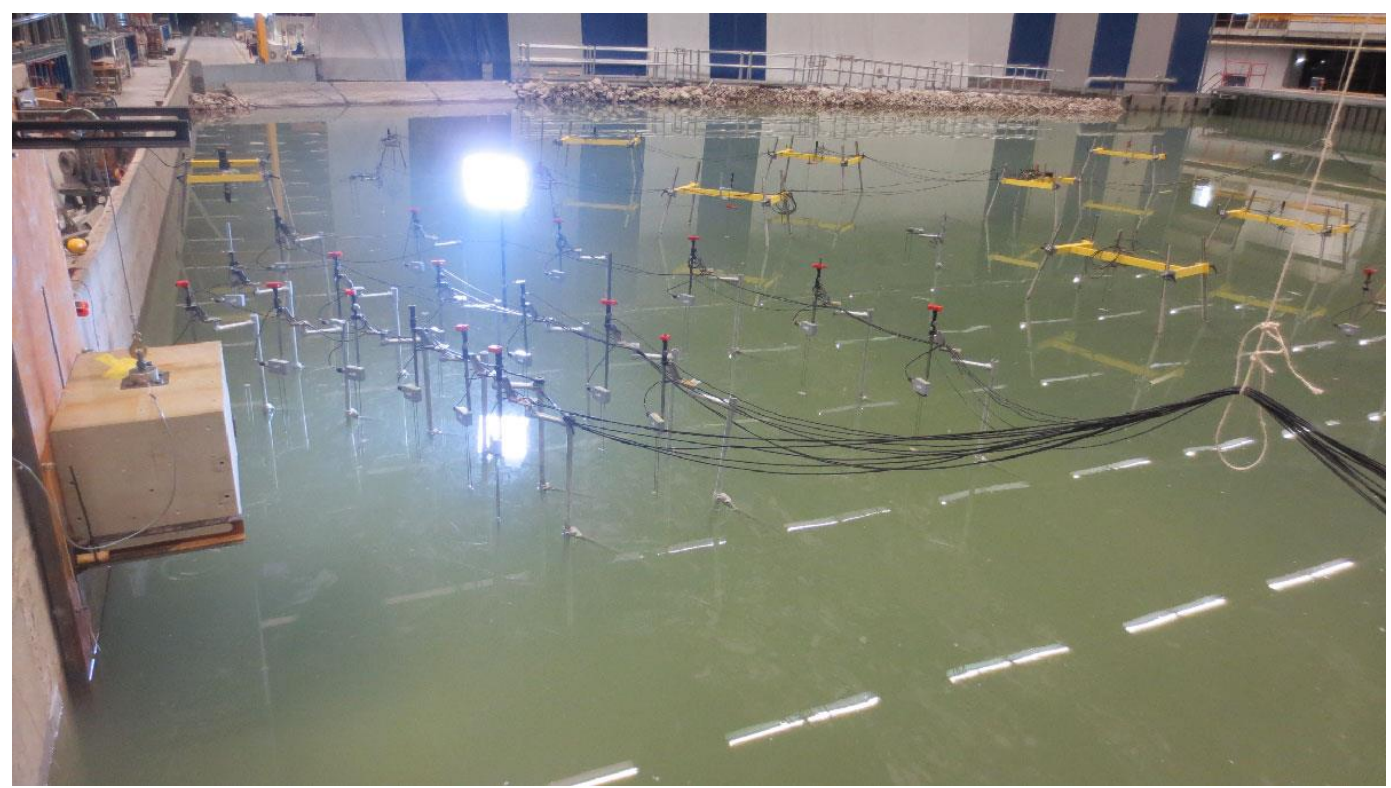

Figure 2. Picture of a gravity-dominated fall experiment (mechanism B) at the wall of the basin with block type 1 in the initial position and most of the 35 wave probes. 


\subsection{Measurement system}

The block kinematics was recorded with a sampling rate of $\approx 74 \mathrm{~Hz}$ with a 9 Degree of Freedom motion sensor (Adafruit BNO055). The sensor was located in a black enclosure and attached to the block surface. Two cameras (5 MP PointGrey ZBR2-PGEHD-50S5C-CS (which recorded at $15 \mathrm{~Hz}$ ) and $2 \mathrm{MP}$ IOIndustries Flare 2M280-CXP (at $100 \mathrm{~Hz}$ )) were used for general observations. The wave features were recorded at $100 \mathrm{~Hz}$ in different directions on one side of the block axis, given that the wave field is symmetric, with up to 35 resistance type wave probes.
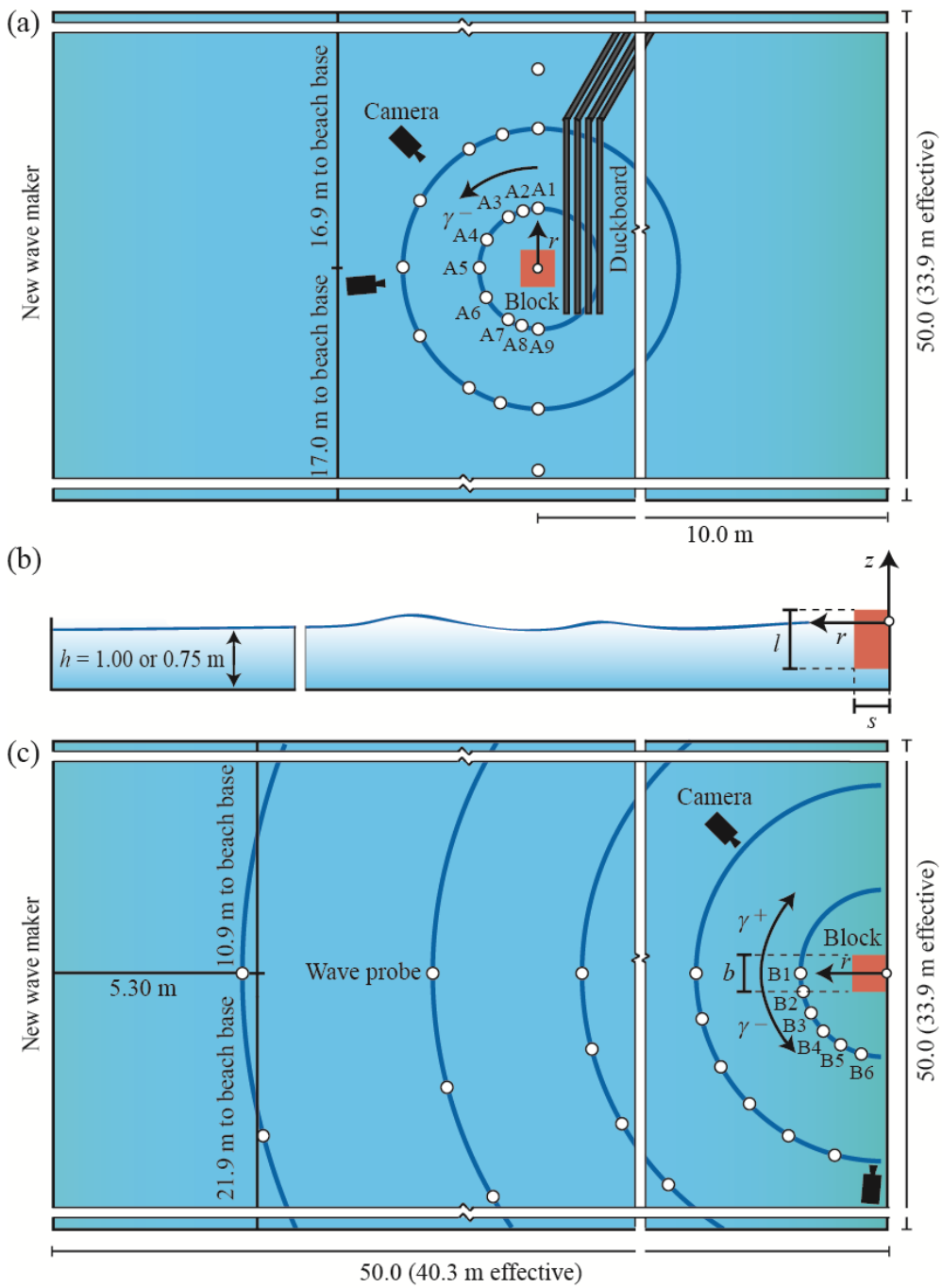

Figure 3. Sketches of experimental set-ups with some wave probes: (a) plan view of capsizing case, (b) side view of a gravity-dominated fall experiment and (c) plan view of a gravity-dominated fall experiment (Heller, 2019).

The coordinate origins of the cylindrical coordinate systems $(r, z, \gamma)$ are shown in Figure 3 . The origins are located for all calving mechanisms in vertical direction $z$ on the water surface. In the horizontal plan the origin is located at the block centre for the capsizing case (Figure 3a) and at the front of the steel plate in the centre of the block in cross-shore direction for all other calving mechanisms (Figure 3c). The wave propagation angle $\gamma$ (angular angle) is defined positive in clockwise direction. The wave probes are numbered anti-clockwise starting at $\gamma=0^{\circ}$ and from smaller to higher radial distance $r$ (Figure 3a,c). Table 2 shows the locations of all wave probes.

The time in all experiments was adjusted such that $t=0 \mathrm{~s}$ corresponds to when the blocks started to move for experiments where they were initially in contact with the surrounding water, or when the blocks reached the water surface when they were initially located above the water body. The raw data of the motion sensor were further analysed in Matlab to transform the accelerations in global coordinates and to derive the block velocities and positions. The wave probe time series were individually shortened to remove data affected by reflection from the basin boundaries. The wave probe data were then filtered with a low-pass filter with a cut off frequency at 9 to $11 \mathrm{~Hz}$. For wave probes A9, A17 and A25 in the capzising experiments and B21/C21, B24/C24 and 
B32/C32 for all fall and overturning experiments a low-pass filter with a cut off frequency at 3.0 or $3.5 \mathrm{~Hz}$ was applied to remove large high-frequency noise. For 3 out of all 2278 wave probe locations the wave probe signals remained noisy after filtering given that the waves were extremely small. These 3 data series were excluded from further analysis.

Table 2. Name and locations of wave probes and cameras.

\begin{tabular}{|c|c|c|c|}
\hline $\begin{array}{l}\text { Iceberg } \\
\text { calving } \\
\text { mechanism }\end{array}$ & Device & $\begin{array}{l}\text { Water } \\
\text { depth } h \\
(\mathrm{~m})\end{array}$ & $\begin{array}{l}\text { Locations in function of the radial distance } r(\mathrm{~m}) \text { and the wave } \\
\text { propagation angle } \gamma\left(\left(^{\circ}\right) \text { (Figure 3a,c) }\right.\end{array}$ \\
\hline Capsizing & $\begin{array}{l}\text { Wave } \\
\text { probes }\end{array}$ & 1.000 & 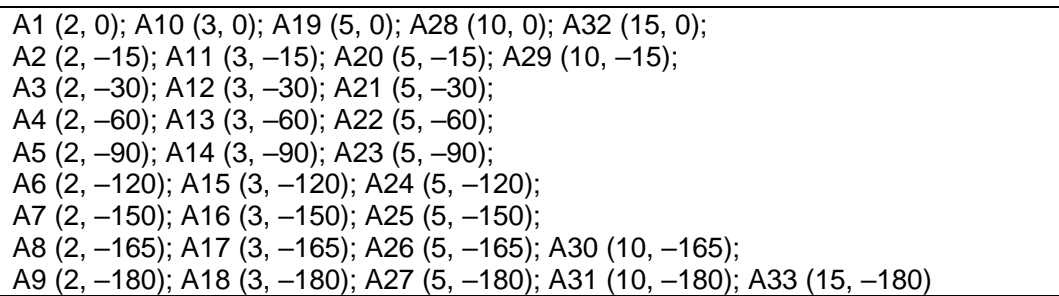 \\
\hline Capsizing & Cameras & 1.000 & $5 \mathrm{MP}$ at $15 \mathrm{~Hz}:(6,-45) ; 2 \mathrm{MP}$ at $100 \mathrm{~Hz}:(6,-95)$ \\
\hline $\begin{array}{l}\text { Fall/ } \\
\text { overturning }\end{array}$ & $\begin{array}{l}\text { Wave } \\
\text { probes }\end{array}$ & 1.000 & 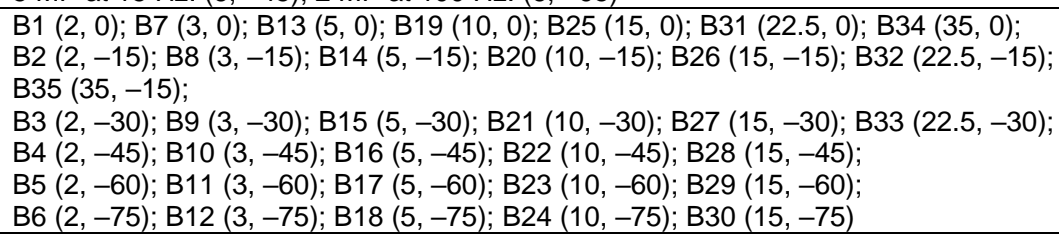 \\
\hline $\begin{array}{l}\text { Fall/ } \\
\text { overturning }\end{array}$ & $\begin{array}{l}\text { Wave } \\
\text { probes }\end{array}$ & 0.750 & 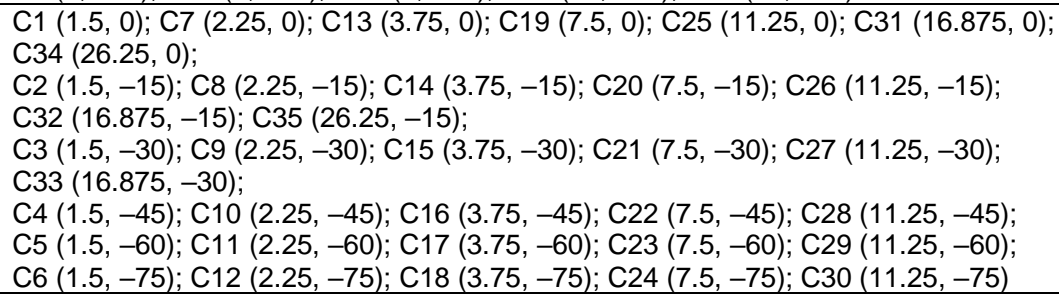 \\
\hline $\begin{array}{l}\text { Fall/ } \\
\text { overturning }\end{array}$ & Cameras & $\begin{array}{l}1.000 \text { and } \\
0.750\end{array}$ & $2 \mathrm{MP}$ at $100 \mathrm{~Hz}:(6,-85) ; 5 \mathrm{MP}$ at $15 \mathrm{~Hz}:(6,45)$ \\
\hline
\end{tabular}

\subsection{Governing parameters}

The following nine governing parameters were considered in the correlations of the iceberg-tsunami features such as the maximum wave heights and their decay with $r$ and $\gamma$.

- Released energy $E$

- Water depth $h$

- Iceberg velocity $V_{s}$

- $\quad$ Iceberg thickness $s$

- $\quad$ Iceberg width $b$

- Iceberg volume $\forall_{s}$

- Iceberg density $\rho_{s}$

- Water density $\rho_{w}$

- Gravitational acceleration $g$

A wider variation of $s$ and $b$ was achieved by changing the orientation of the two block types 1 and 2 in the initial position (Table 1). The velocity $V_{s}$ corresponds to the fastest moving section of the block and was derived based on the motion sensor data as 0.27 to $4.17 \mathrm{~m} / \mathrm{s}$ over all experiments. The density $\rho_{s}$ changed slightly with the attachments to the block (Table 1). The parameter $E$ was introduced after the test campaign varying between 6 and $980 \mathrm{~J}$ over all experiments making this parameter instrumental to correlate very large and very small waves. This energy corresponds to the energy difference of the iceberg between the initial and final positions and is thus the maximum available energy to be transferred into tsunami energy. The theoretical expressions and values for $E$ were derived by Heller et al. (2019b) in function of the iceberg calving mechanism, iceberg geometry and initial position relative to the water surface.

The nine governing parameters can be expressed in dimensionless form based on the reference quantities $g, h$ and $\rho_{w}$ (Buckingham, 1914). This results in the following six dimensionless parameters and ranges covered by the experiments (Attili, 2019):

- $\quad$ Relative released energy: $0.0006 \leq E_{r}=E /\left(\rho_{w} g h^{4}\right) \leq 0.3157$

- Froude number: $0.09 \leq \mathrm{F}=V_{s} /(g h)^{1 / 2} \leq 1.33$ 
- $\quad$ Relative iceberg thickness: $0.25 \leq S=s / h \leq 0.67$

- $\quad$ Relative iceberg width: $0.50 \leq B=b / h \leq 1.07$

- $\quad$ Relative iceberg volume: $0.10 \leq V=V_{s} / h^{3} \leq 0.47$

- Relative density: $0.91 \leq D=\rho_{s} / \rho_{w} \leq 0.94$

Scale effects due to the kinematic viscosity $v_{w}$ and surface tension $\sigma_{w}$ were neglected for the analysed wave parameters in this Froude scaling experiments given that the Weber number $\mathrm{W}=\rho_{w} g h^{2} / \sigma_{w} \geq 75,552$ and Reynolds number $\mathrm{R}=g^{1 / 2} h^{3 / 2} / v_{w} \geq 2,033,835$ in the experiments were large and satisfied the limitations $\mathrm{W} \geq$ 5,000 and $R \geq 300,000$ applicable for the physically closely related phenomenon of subaerial landslide-tsunamis (Heller et al., 2008). The absolute and relative measurement errors of most dimensional and dimensionless parameters are given in Heller et al. (2019b). The six dimensionless parameters are used in the Results and Discussion section to correlate the maximum wave heights.

\section{RESULTS AND DISCUSSION}

Figure 4 shows the free water surface $\eta$ versus time $t$ of five selected experiments involving all five iceberg calving mechanisms. These wave profiles were all measured at relative radial distance $r / h=2$ (Figure 3 and Table 2). The scales on the $y$-axes in Figure 4 vary by up to a factor of 20. The wave magnitudes significantly differ for the mechanisms $A$ to $E$; the gravity-dominated overturning mechanism $D$ results in the largest tsunamis followed by the gravity-dominated fall mechanism $B$. The three remaining mechanisms resulted in up to a factor of 27 smaller waves (Heller et al., 2019b). Further, the wave trains consist of several nonlinear waves for all mechanisms, similar as for subaerial landslide-tsunamis (Heller and Spinneken, 2015). The largest wave amplitude is observed in the middle of the wave train for the slower moving mechanisms A, C and E. For the gravity-dominated mechanisms $B$ and $D$ the largest wave is observed earlier in the wave train.

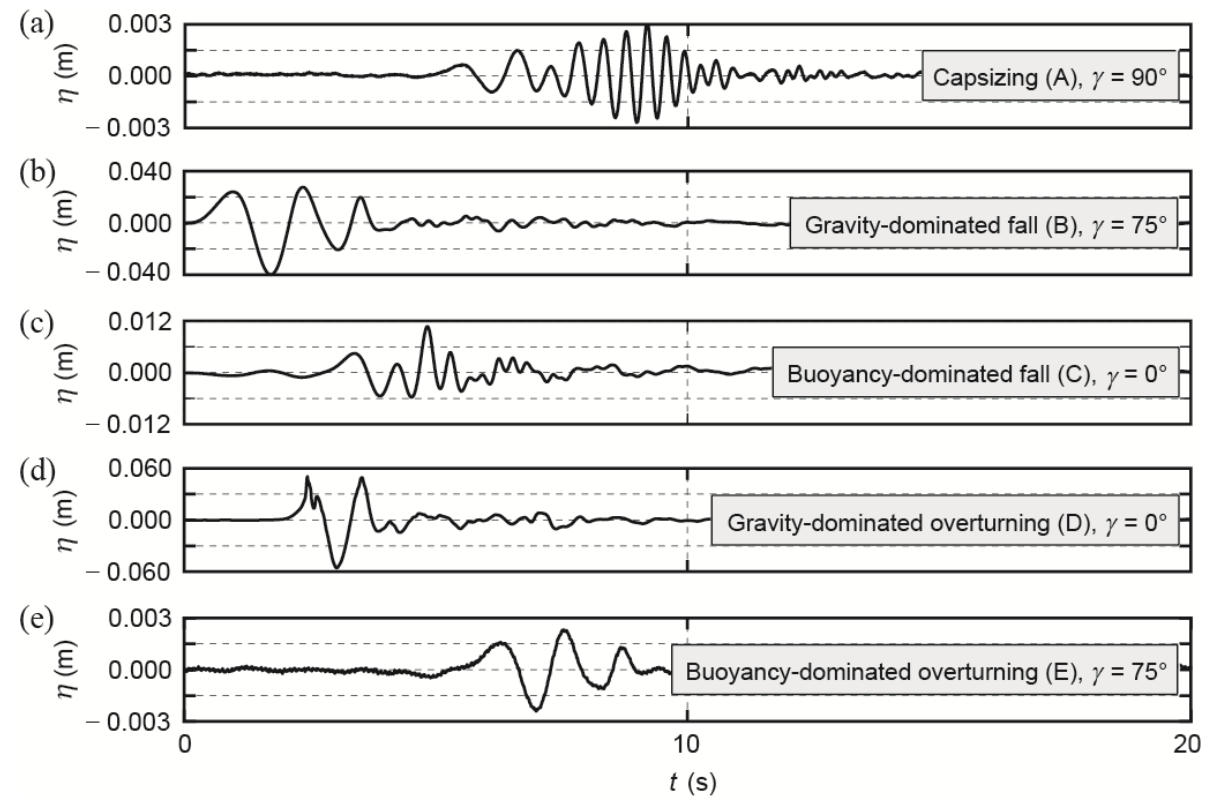

Figure 4. One selected iceberg-tsunami profile for each calving mechanism $A$ to $E$. These tsunami profiles were recorded at $(r / h=2, \gamma)$ where the maximum wave height $H_{M}$ was measured. (a) Capsizing, (b) gravitydominated fall, (c) buoyancy-dominated fall, (d) gravity-dominated overturning and (e) buoyancy-dominated overturning mechanism. The scales on the $y$-axes change by up to a factor of 20 (Heller et al., 2019b).

Figure 5 shows the relative maximum wave heights $H_{M} / h$ for all 66 experiments versus the six dimensionless parameters. Shown are correlations for each individual iceberg calving mechanism (Figure 5ae) and for all mechanisms combined (Figure 5f). The best correlations were found with a regression analysis based on the least-square approach with the Matlab function Isqcurvefit. Some restrictions were imposed on the exponents (e.g. > 0 for most of them) to obtain physical meaningful results (Attili, 2019). The empirical equations and coefficients of determination $R^{2}$ resulting from Figure 5 are

$\begin{array}{llrl}\text { Capsizing } & \frac{H_{M}}{h}=1.39\left(E_{r}^{0.26} \mathrm{~F}^{1.73} S^{0.20} B^{0.20} V^{0.48} D^{-1.74}\right)^{0.92} & \left(R^{2}=0.49\right) \\ \text { Gravity-dominated fall } & \frac{H_{M}}{h}=0.25\left(E_{r}^{0.20} \mathrm{~F}^{1.31} S^{0.60} B^{1.62} V^{0.20} D^{0.15}\right)^{0.50} & \left(R^{2}=0.95\right) \\ \text { Buoyancy-dominated fall } & \frac{H_{M}}{h} & =1.41\left(E_{r}^{0.20} \mathrm{~F}^{1.36} S^{0.10} B^{0.30} V^{0.48} D^{-1.42}\right)^{0.98} & \left(R^{2}=0.64\right)\end{array}$


Gravity-dominated overturning $\quad \frac{H_{M}}{h}=0.27\left(E_{r}^{0.20} \mathrm{~F}^{0.92} S^{0.47} B^{0.91} V^{0.23} D^{0.22}\right)^{0.50}$

$\left(R^{2}=0.92\right)$

Buoyancy-dominated overturning $\frac{H_{M}}{h}=0.13\left(E_{r}^{0.23} \mathrm{~F}^{1.65} S^{1.27} B^{0.40} V^{0.20} D^{-0.98}\right)^{0.50}$

$\left(R^{2}=0.95\right)$
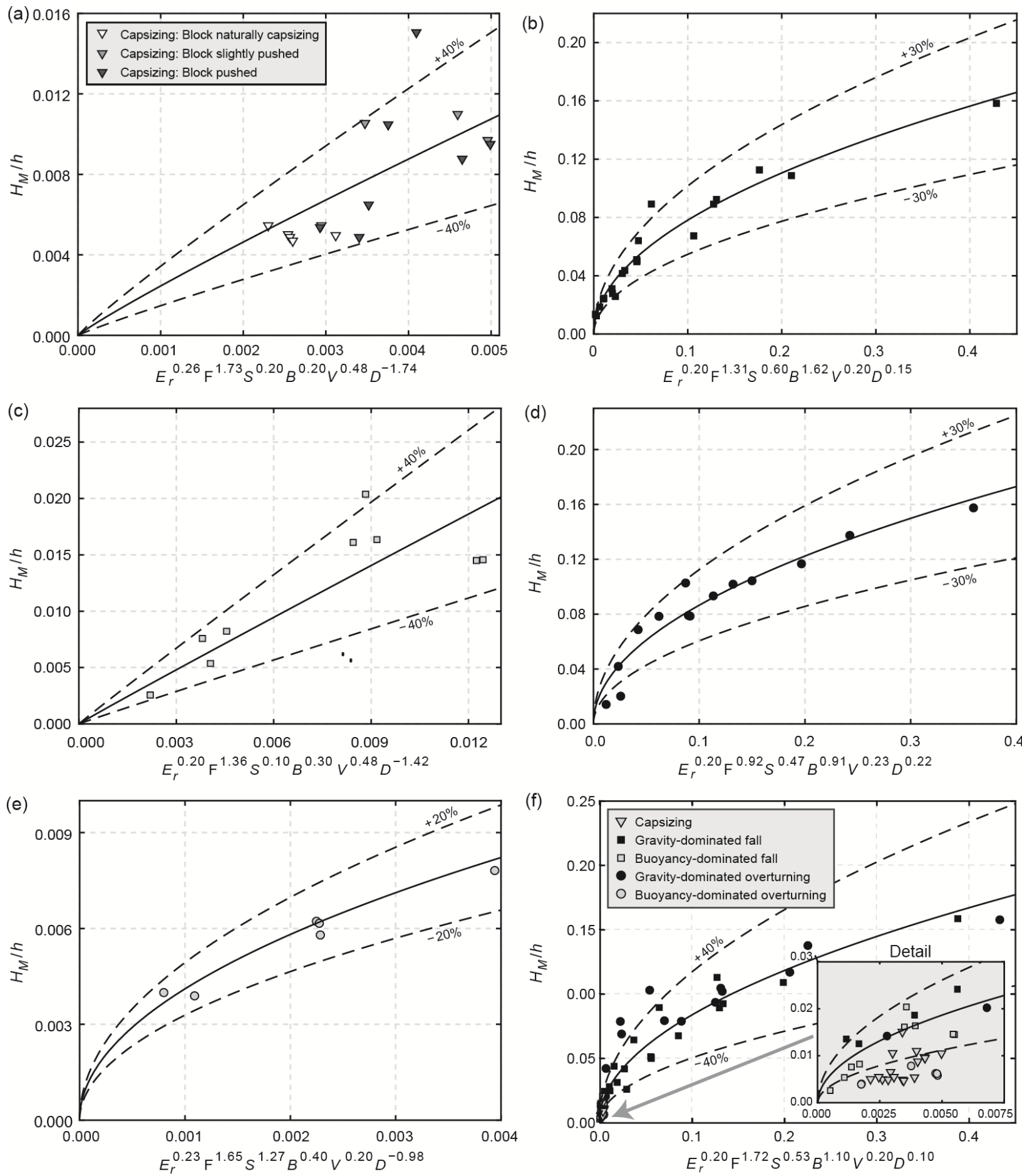

Figure 5. Maximum relative wave heights $H_{M} / h$ versus dimensionless parameter combinations for (a) capsizing with (-) Eq. [1] and (--) $\pm 40 \%$ deviation $\left(R^{2}=0.49\right)$, (b) gravity-dominated fall with (-) Eq. [2] and $(--) \pm 30 \%$ deviation $\left(R^{2}=0.95\right)$, (c) buoyancy-dominated fall with $(-)$ Eq. [3] and $(--) \pm 40 \%$ deviation $\left(R^{2}=\right.$ 0.64), (d) gravity-dominated overturning with (-) Eq. [4] and (--) $\pm 30 \%$ deviation $\left(R^{2}=0.92\right)$, (e) buoyancydominated overturning with (-) Eq. [5] and (--) $\pm 20 \%$ deviation $\left(R^{2}=0.95\right)$ and (f) all mechanisms combined with (-) Eq. [6] and (--) $\pm 40 \%$ deviation $\left(R^{2}=0.92\right)$. For the legend see subfigure (f). 

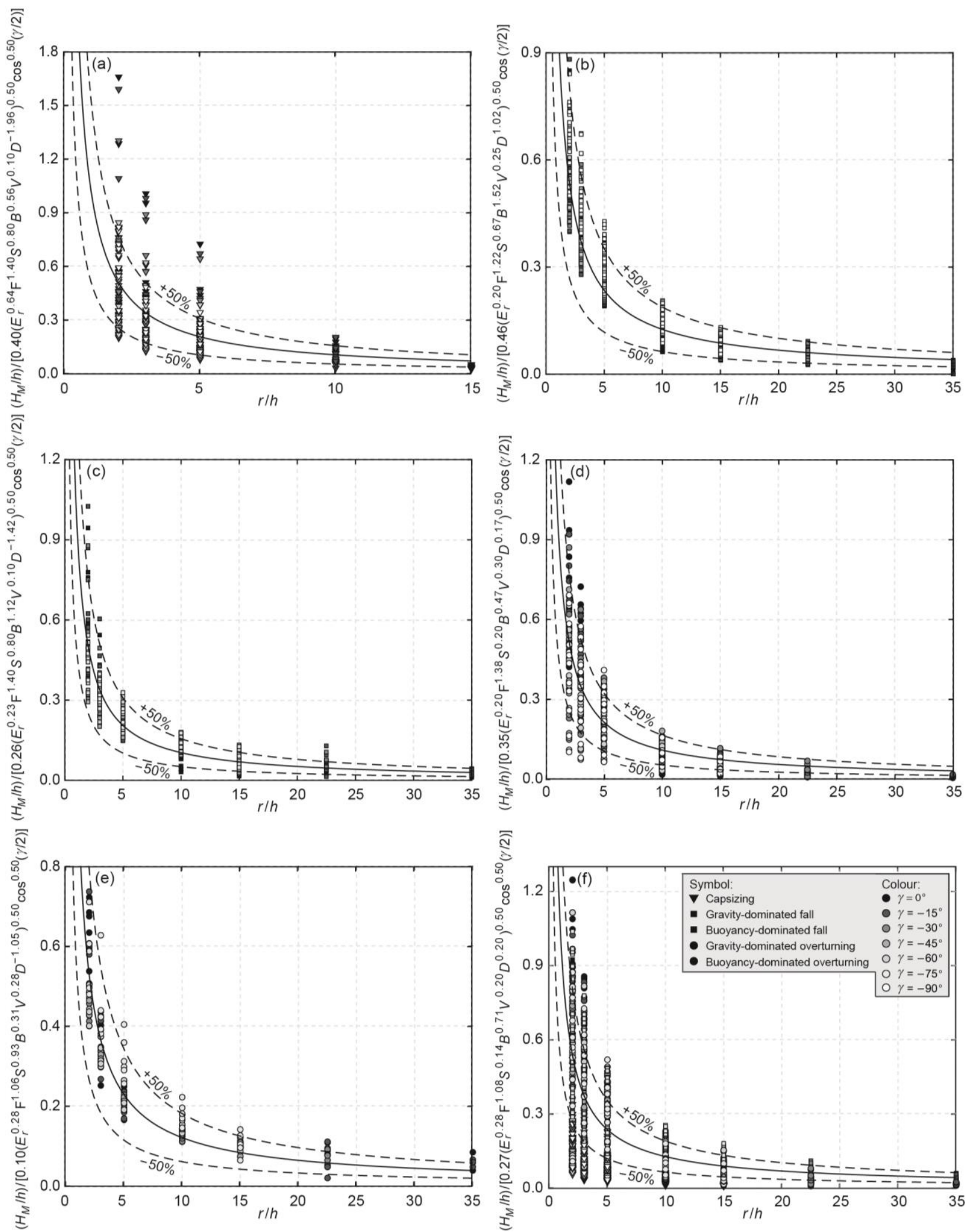

Figure 6. Normalised relative maximum wave height $H_{M} / h$ decay for all experiments with the relative distance $r / h$ : (a) capsizing with (-) Eq. [7] and (--) $\pm 50 \%$ deviation $\left(R^{2}=0.40\right)$, (b) gravity-dominated fall with $(-)$ Eq. [8] and (--) $\pm 50 \%$ deviation $\left(R^{2}=0.93\right)$, (c) buoyancy-dominated fall with (-) Eq. [9] and (--) $\pm 50 \%$ deviation

$\left(R^{2}=0.84\right)$, (d) gravity-dominated overturning with (-) Eq. [10] and $(--) \pm 50 \%$ deviation $\left(R^{2}=0.86\right),(e)$ buoyancy-dominated overturning with (-) Eq. [11] and (--) $\pm 50 \%$ deviation $\left(R^{2}=0.89\right)$ and (f) all mechanisms combined with (-) Eq. [12] and (--) $\pm 50 \%$ deviation $\left(R^{2}=0.80\right)$. For the legend see subfigure (f). 
The most important parameter in Eqs. [1] to [6] is $F$ with a large exponent in the range of 0.92 to 1.73 . Further important are the relative slide width $B$, with an exponent of up to 1.62 , as well as $E_{r} . E_{r}$ is influential due to the combination of the exponent $\approx 0.20$ with the large range of $E_{r}$ over nearly three orders of magnitude. Generally speaking, the influences of $S, V$ and $D$ on the maximum wave height are significantly smaller. The pre-sign of the exponent of $D$ is positive for the gravity-dominated mechanisms and negative for the remaining three mechanisms, however, the overall influence of $D$ on $H_{M} / h$ is still small given that it varies only in the range 0.91 to 0.94 (Section 2.3). The data typically scatter $\pm 30 \%$ relative to the predictions with a particularly tight fit achieved for the buoyancy-dominated overturning mechanism in Figure 5(e). Figure 5 confirms that the tsunami heights generated by mechanisms $B$ and $D$ (gravity-dominated) were roughly an order of magnitude larger than for mechanisms A, C and E over all conducted experiments. The correlation in Figure 5(f) based on Eq. [6] simplifies the prediction with one equation describing all mechanisms combined. Most data lie within the $\pm 40 \%$ bounds, however, the insert reveals that Eq. [6] tends to overpredict the buoyancy-dominated and capsizing mechanisms and therefore operates on the save side for these mechanisms.

The decays of the relative maximum wave heights $H_{M} / h(r / h, \gamma)$ for all 66 experiments for each individual iceberg calving mechanism and all mechanisms combined are shown in Figure 6 . The corresponding empirical equations were again found with the Matlab function Isqcurvefit resulting in

$$
\begin{array}{lllll}
\text { Capsizing } & \frac{H_{M}}{h}\left(\frac{r}{h}, \gamma\right) & =0.40\left(E_{r}^{0.64} \mathrm{~F}^{1.40} S^{0.80} B^{0.56} V^{0.10} D^{-1.96}\right)^{0.50}\left(\frac{r}{h}\right)^{-0.99} \cos ^{0.5}\left(\frac{\gamma}{2}\right) & \left(R^{2}=0.40\right) & {[7]} \\
\text { Gravity-dominated fall } & \frac{H_{M}}{h}\left(\frac{r}{h}, \gamma\right) & =0.46\left(E_{r}^{0.20} \mathrm{~F}^{1.22} S^{0.67} B^{1.52} V^{0.25} D^{1.02}\right)^{0.50}\left(\frac{r}{h}\right)^{-0.91} \cos \left(\frac{\gamma}{2}\right) & \left(R^{2}=0.93\right) & {[8]} \\
\text { Buoyancy-dominated fall } & \frac{H_{M}}{h}\left(\frac{r}{h}, \gamma\right) & =0.26\left(E_{r}^{0.23} \mathrm{~F}^{1.40} S^{0.80} B^{1.12} V^{0.10} D^{-1.42}\right)^{0.50}\left(\frac{r}{h}\right)^{-0.98} \cos ^{0.5}\left(\frac{\gamma}{2}\right) & \left(R^{2}=0.84\right) & {[9]}
\end{array}
$$

The parameters $F, B$ and $E_{r}$ are also dominant in Eqs. [7] to [12] and $S, V$ and $D$ play a less significant role. The data in Figure 6 follow the predictions based on Eqs. [7] to [12] reasonably well and most data lie within the $\pm 50 \%$ bounds. Particularly striking for all mechanisms is the wave decay approximately following $(r / h)^{-1.0}$, corresponding both to the theoretically expected decay for a wave created by a point source propagating on a spatial water surface (Kranzer and Keller, 1959) and the decay previously found for landslide-tsunami experiments conducted in a basin (Heller and Spinneken, 2015). Note that the outliers in Figure 6(a) are from the pushed block experiments. The wave decay with the wave propagation angle $\gamma$ is expressed with the cosinus function, similar as in some landslide-tsunami studies (Huber and Hager, 1997; Heller and Spinneken, 2015). A reasonably good fit for the data of all calving mechanisms combined is achieved in Figure 6(f) considering the variety of underlying physics involved in the five iceberg calving mechanisms. The corresponding Eq. [12] results in a coefficient of determination of $R^{2}=0.80$. However, the data scatter is particularly large in proximity of the iceberg calving location at $r / h=2$ where water splashes reached the wave probes in some of the experiments.

\section{CONCLUSIONS AND OUTLOOK}

Unique large-scale experiments have been conducted in a $50 \mathrm{~m} \times 50 \mathrm{~m}$ basin. 66 iceberg-tsunami experiments with up to $187 \mathrm{~kg}$ heavy blocks under variation of the iceberg volume, geometry, kinematics and initial position relative to the water surface have been conducted. The blocks interacted with the surrounding water through five iceberg calving mechanisms namely: A: capsizing, B: gravity-dominated fall, C: buoyancy-dominated fall, $\mathrm{D}$ : gravity-dominated overturning and $\mathrm{E}$ : buoyancy-dominated overturning. The main conclusions are:

- The tsunami heights generated by mechanisms B and D (gravity-dominated) are roughly an order of magnitude larger than from mechanisms A, C and E. Icebergs of a given volume and geometry released above the water surface are therefore significantly more hazardous in terms of tsunami generation than neutrally buoyant icebergs or icebergs released underwater.

- The tsunami features were expressed in function of six dimensionless parameters where the Froude number $F$, the relative iceberg width $B$ and the relative released energy $E_{r}$ were found to be the most dominant ones.

- The maximum tsunami heights decay approximately with the relative distance $(r / h)^{-1.0}$, in agreement with theory and some landslide-tsunami studies.

- Empirical equations for the maximum wave height and its decay with the relative propagation distance $r / h$ and wave propagation angle $\gamma$ are presented for each individual iceberg calving mechanism and all mechanisms combined to support preliminary iceberg-tsunami hazard assessment. 
Ongoing and future work aims to analyse more wave parameters including the maximum wave amplitudes and periods. The iceberg-tsunamis will also be compared in more detail with landslide-tsunamis (Heller and Spinneken, 2015). A numerical model is also under development which, in principle, is capable of simulating all five iceberg calving mechanisms and iceberg-tsunamis (Chen et al., 2019a,b).

\section{ACKNOWLEDGEMENTS}

Thanks go to Miss Elsa Büchner, Mr Daniel Fox, Miss Lina Grummel and Mr Sheng Yang for their contributions within their BEng and MSc projects. The personnel at Deltares is acknowledged for the excellent support prior and during the test campaign. The data presented herein will be made available on the HYDRALAB+ website together with the data storage report Heller (2019). This project has received funding from the European Union's Horizon 2020 research and innovation programme under grant agreement No 654110, HYDRALAB+.

\section{REFERENCES}

Attili, T. (2019). Analysis of iceberg-tsunamis from large-scale experiments. MSc thesis. University of Pisa, Italy. Benn, D.I., Warren, C.R. and Mottram, R.H. (2007). Calving processes and the dynamics of calving glaciers. Earth-Science Reviews 82, 143-179.

Buckingham, E. (1914). On physically similar systems - Illustrations of the use of dimensional equations. Physical Review 4, 345-376.

Burton, J.C., Amundson, J.M., Abbot, D.S., Boghosian, A., Cathles, L.M., Correa-Legisos, S., Darnell, K.N., Guttenberg, N., Holland, D.M. and MacAyeal, D.R. (2012). Laboratory investigations of iceberg capsize dynamics, energy dissipation and tsunamigenesis. Journal of Geophysical Research 117(F01007).

Chen, F., Heller, V. and Briganti, R. (2019a). Numerical modelling of tsunamis generated by iceberg calving validated with large-scale laboratory experiments (in preparation).

Chen, F., Heller, V. and Briganti, R. (2019b). Numerical simulation of tsunamis generated by iceberg calving. $38^{\text {th }}$ IAHR World Congress.

Dykes, R.C., Brook, M.S. and Lube, G. (2016). A major ice-calving event at Tasman Glacier terminus, Southern Alps, 22 February 2011. Journal of the Royal Society of New Zealand 47(4), 336-343.

Enderlin, E.M., Howat, I.M., Jeong, S., Noh, M.-J., van Angelen, J.H. and van den Broeke, M.R. (2014). An improved mass budget for the Greenland ice sheet. Geophysical Research Letters 41, 866-872.

Hanna, E., Navarro, F.J., Pattyn, F., Domingues, C.M., Fettweis, X., Ivins, E.R., Nicholls, R.J., Ritz, C., Smith, B., Tulaczyk, S., Whitehouse, P.L. and Zwally, H.J. (2013). Ice-sheet mass balance and climate change. Nature 498, 51-59.

Heller, V. (2019). Tsunamis due to ice masses - Different calving mechanisms and linkage to landslide-tsunamis - Data storage report. Data storage report of HYDRALAB+ test campaign (online http://hydralab.eu/research--results/ta-projects/project/hydralab-plus/11/).

Heller, V., Attili, T., Chen, F., Brühl, M., Gabl, R., Chen, X., Wolters, G. and Fuchs, H. (2019a). Large-scale iceberg-tsunami experiments. Proceedings of the HYDRALAB+ Joint User Meeting, Bucharest, Romania, 67-77, Henry, P.-Y., Breteler, M.K. eds.

Heller, V., Chen, F., Brühl, M., Gabl, R., Chen, X., Wolters, G. and Fuchs, H. (2019b). Large-scale experiments into the tsunamigenic potential of different iceberg calving mechanisms. Scientific Reports 9:861.

Heller, V., Hager, W.H. and Minor, H.-E. (2008). Scale effects in subaerial landslide generated impulse waves. Experiments in Fluids 44(5), 691-703.

Heller, V. and Spinneken, J. (2015). On the effect of the water body geometry on landslide-tsunamis: physical insight from laboratory tests and 2D to 3D wave parameter transformation. Coastal Engineering 104(10), 113-134.

Huber, A. and Hager, W.H. (1997). Forecasting impulse waves in reservoirs. Proceeding 19th Congrès des Grands Barrages, Florence, ICOLD, Paris, 993-1005.

Kranzer, H.C. and Keller, J.B. (1959). Water waves produced by explosions. Journal of Applied Physics 30(3), 398-407.

Lüthi, M.P. and Vieli, A. (2016). Multi-method observation and analysis of a tsunami caused by glacier calving. The Cryosphere 10, 995-1002.

Massel, S.R. and Przyborska, A. (2013). Surface wave generation due to glacier calving. Oceanologia 55(1), 101-127.

Minowa, M., Podolskiy, E.A., Sugiyama, S., Sakakibara, D. and Skvarca, P. (2018). Glacier calving observed with time-lapse imagery and tsunami waves at Glaciar Perito Moreno, Patagonia. Journal of Glaciology 64(245), 362-376.

N24 (2009). Tsunami Greenland - Tsunami Groelândia 1995. Online under https://www.youtube.com/watch?v=z8LWSOPwkn8 (accessed 28.07.2019, in German).

Vaňková, I. and Holland, D.M. (2016). Calving signature in ocean waves at Helheim Glacier and Sermilik Fjord, East Greenland. Journal of Physical Oceanography 46(10), 2925-2941. 